\title{
Reflexões Sobre Cognição/Subjetivação no Ciberespaço na Perspectiva da Complexidade
}

\section{Reflections on cognition/subjectivation in the cyberspace from the complexity perspective}

Resumo: O artigo trata de reflexões teóricas como contribuição para ampliar a abordagem ao tema do processo de cognição no espaço digital e sua relação com os pressupostos do paradigma da complexidade. O foco do artigo é colocado na idéia de Substância Única de Espinosa com a justificativa que esse, sendo um pensamento integrador, e portanto, complexo, pode ajudar a romper com a herança cartesiana responsável por uma forte fragmentação. A partir dessas idéias seminais, o texto se desdobra nas considerações sobre a emergência da cibernética, com ênfase na II Cibernética, principalmente no que diz respeito à contribuicão de Von Foerster para o desenvolvimento das teorias biológicas complexas de $\mathrm{H}$. Atlan, H. Maturana e F. Varela. Os conceitos envolvidos nessas teorias como complexificação pelo ruído e autopoiesis são pensados à luz das idéias de Espinosa como também, considerando-se a experiência empírica da autora, são ilustrados por breves exemplos. Palavras-chave: Substância única. Espaço digital. Complexidade. Autopoiesis. Complexificação pelo ruído.

Abstract: The article deals with theoretical reflections as a contribution to wide the approach to the theme of the cognition process in a digital space and its relationship with the assumptions of the complexity paradigm. The article focus is placed on the Idea of the Unique Substance from Espinosa with the argumentation that this philosopher had an integrative thought and, therefore, complex, can help in breaking with the strong Cartesians tradition of fragmentation. Departing from these seminal ideas, the text follows through the considerations on the emergency of cybernetics with the emphasis in the II Cybernetics mainly in relation to the contributions from Von Foerster for the development of biological complex theories by $\mathrm{H}$. Atlan and H. Maturana/F. Varela. The involved concepts in these theories such as complexification from the noise and autopoiesis are reflected at the light of de Spinoza ideas as well, considering the empirical experience of the author, are ilustrated with some examples.

Keywords: Unique substance. Digital space. Complexity. Autopoiesis. Complexifcation from noisy.

PELLANDA, Nize Maria Campos. Reflexões Sobre Cognição/ Subjetivação no Ciberespaço na Perspectiva da Complexidade. Informática na Educação: teoria \& prática, Porto Alegre, v. 12, n. 2, p. 35-44, jul./dez. 2009.

\author{
Nize Maria Campos Pellanda
}

\section{I ntrodução}

“O corpo humano tem necessidade para a sua conservação, de muitos outros corpos, pelos quais é infinitamente como que regenerado." Baruch Espinosa

0 que pretendo com esse artigo é fazer uma contribuição de ordem ontológica e epistemológica para ampliar o quadro teórico no qual tem sido pensadas as questões da informática educativa e sua relação com a cognição. Trata-se de um texto teórico ainda que seja atravessado pela minha experiência como pesquisadora em anos de trabalhos com projetos de inclusão digital com crianças e adolescentes de famílias de baixa renda. Nesses projetos havia uma preocupação primordial de focar na inseparabilidade construção de conhecimento/construção de subjetividade.

$O$ ponto de partida desse artigo é Espinosa, o grande filósofo do século XVII, para quem havia uma substância única no universo e, consequentemente, todas as coisas que existem fazem parte dessa realidade estando profundamente conectadas. Nessa concepção, portanto, conhecer é estar conectado. Ou ainda, na linguagem espinosiana, conhecer é afectarse. (ESPINOSA, 1982, DELEUZE, 2002). Com essa atitude enfatizo um rompimento com a tradição cartesiana responsável por uma ciência e uma cultura marcadas por uma profunda 
fragmentação, o que teve conseqüências epistêmicas, ontológicas, sociais, éticas e políticas de profundo alcance na vida da humanidade nos tempos que seguiram à modernidade.

As idéias de Espinosa são incrivelmente contemporâneas pois elas estão no coração do paradigma da complexidade na medida em que esse paradigma se assenta no pressuposto básico do imbricamento das diferentes dimensões da realidade. Delas destaco dois eixos em torno dos quais organizarei o meu texto: o primeiro, como já referido, é o da Substância Única e o segundo é o conceito de causa sui (causa de si mesmo) que pode ser pensado isomorficamente à luz do princípio de auto-organização, elemento lógico organizador do Movimento de Auto-Organização (DUPUY, 1996). Nesse sentido, pretendo estabelecer pontes entre o pensamento de Espinosa e as teorias da complexidadena contemporaneidade, principalmente as teorias biológicas que se seguiram ao movimento cibernético, notadamente as teorias da Complexificação pelo Ruído (ATLAN, 1972) e a Biologia do Conhecer (MATURANA; VARELA, 1980). Essas teorias são chamadas de complexas devido, primordialmente, ao fato de não separarem o processo de conhecer do processo de viver.

$\mathrm{Na}$ perspectiva de uma substância única, portanto, os seres humanos seriam modos dessa substância única e não seriam diferentes de outros modos que são inanimados. Seres e coisas se compõem uns com os outros de tal forma que podemos lembrar o projeto da cibernética que usa um mesmo dispositivo lógico para pensar seres vivos, coisas e natureza. Com esse pressuposto em mente pretendo pensar a técnica de forma complexa, ou seja, como uma composição entre os seres humanos e máquinas à maneira de afecções. Essas composições e afecções potencializariam os seres humanos ao poderem se pensar com instrumentos novos e instigantes em espaços que ampliam suas potencialidades. Esses movimentos internos de auto-constituição dos sujeitos são possíveis graças à presença do princípio de auto-organização e o ambiente digital age como um conjunto de dispositivos desafiadores, o que provocaria movimentos nos sujeitos envolvidos que levam a reconfigurações.

Com essas idéias seminais, pretendo com esse artigo fazer considerações teóricas a respeito das relaçõessereshumanos/tecnologias digitais para pensar o espaço digital como um ambiente no qual podemos nos constituir a nós mesmos através das respostas às perturbações que, segundo Maturana (1980, 1997), nunca são instrutivas mas desencadeadoras de movimentos de auto-organização e, portanto, de transformações. Voltaremos a isso. E ainda, pensando nos termos de Atlan, podemos inferir um processo de complexificação que tal ambiente proporcionaria pelo papel jogado por uma "[ . . . ] lógica da hipercomplexidade [ . . . ]" (ATLAN, 1992, p. 159).

A partir de todas essas considerações iniciais explicito meu problema para a construção desse texto: - Como podemos pensar nas potencialidades cognitivo-ontológicas do espaço digital à luz do pensamento de Espinosa de forma profundamente articulada com os pressupostos cibernéticos, principalmente no que diz respeito aos desdobramentos das teorias biológicas complexas?

Para perseguir a proposta teórica explicitada farei, à maneira complexa, uma tessitura de fios, procurando jogar com os pressupostos teóricos espinosianos e cibernéticos, de modo a não desfocar em nenhum momento da idéia de substância única e do princípio de autoorganização como constituintes de realidade, de sujeito e de conhecimento.

\section{Complexidade: a gênese de um paradigma}

Um novo paradigma científico que emerge a partir do final do século XIX coloca desafios severos às práticas da ciência. O paradigma da complexidade teve uma longa gestação através da história e acarreta uma reformulação radical na sociedade, na política, nas questões do conhecimento e para a própria ontogenia dos seres humanos. Esse paradigma começa a emergir com mais intensidade a partir do movimento cibernético dos anos 40 e 50 . Essa fase histórica viu nascer um dos movimentos científicos mais instigantes da História da Ciência. Esse movimento foi antecedido e preparado por descobertas fundamentais que revolucionam a ciência a partir do final do século XIX com o aparecimento das equações não-lineares e de ciências que levavam em consideração o tempo, como a termodinâmica e a biologia evolutiva. No início do século XX, a Física Quântica e a Psicanálise perturbam 
ainda mais o status quo científico ao inverter a lógica do aparente e substancial para priorizar o latente e relacional. Trata-se de uma passagem do ser para o devir o que acarreta questões epistemológicas e metodológicas de fundo. Essas descobertas tem em comum o rompimento com uma abordagem linear ao se enfrentarem os cientistas com objetos cada vez mais complexos e instáveis. O movimento cibernético, ao tratar das questões do funcionamento interno dos sistemas complexos, traz os princípios de autoorganização e feedback como elementoschave para entendermos uma realidade desubstancializada e circular em fluxo constante que se constitui continuamente com o efetivo operar de um sistema.

No entanto, podemos recuar ainda mais em busca da gênese dessa cultura chegando aos pré-socráticos onde encontramos em Heráclito um pensamento genuinamente complexo. O fragmento 91: "Não nos banhamos jamais duas vezes no mesmo rio (apud SCHÜLLER, 2000, p.133) é um claro exemplo de entendimento da vida como devir em transformação constante.

No século XVII, contemporâneo, portanto, do cartesianismo, Espinosa enfrenta o dualismo de Descartes com sua visão integradora da realidade expressa principalmente na inseparabilidade mente/corpo e na idéia de substância única. Nessa abordagem, o papel dos afectos é fundamental para o conhecimento pois cumpriria a função de ligar as várias partes do mesmo sistema. O que Espinosa coloca na Ética é a idéia de um universo intricado em eterno devir de onde emerge a questão da não-separação do conhecimento e ser (ESPINOSA, 1983).

É absolutamente impressionante a perspicácia de Espinosa em pensar coisas que seriam fundamentais para os teóricos da complexidade na atualidade. As idéias de causa sui poderia ser comparada com o conceito de auto-organização do pensamento cibernético e a de conatus (potência singular de cada ser ou esforço para devir) no sentido da autoorganização e autonomia de cada ser como senhor de seu destino.

Para Espinosa (1983), existe uma única substância no Universo e, por isso, somos afetados continuamente pelo que está em nosso redor. Somos afectados mas não determinados. Essas afecções dependem do que fazemos com elas. Essa idéia é central no modelo cibernético da cognição pensada por Maturana e Varela (1990) que mostram os seres vivos como sistemas fechados para a informação com os sistemas sujeitos a perturbações que não são instrutivas mas que apenas perturbam levando o sistema a novas reconfigurações. Nosso conatus, se bem aproveitado, faz com que nos potencializemos com essas afecções e, ao contrário, se não tomamos as rédeas de nossa vida, nossa potência de agir e conhecer diminui. Aqui então, uma questão básica no nosso esquema argumentativo.

No final do século XIX, Nietzsche fazendo filosofia a martelo inaugura um processo de desconstrução da modernidade que abriu caminho para outros pensadores. Nietzsche teve o papel inegável de arauto da complexidade ao atacar energicamente os pilares mais caros da modernidade: a representação, a formalização, a hegemonia do aparente sobre o latente e a negação da autonomia e da agência humanas.

Em uma das melhores biografias do filósofo escreve Safranski (2001, p. 47): “Ele não se limitara a desenvolver pensamentos, mas mostrara como os pensamentos nascem da vida, e tornam para a vida modificandoos." Pergunto-me: isso não seria a própria afirmação da vida sobre todo o resto expresso em uma equação cibernética, ou seja, através da recursividade? Subjaz aí a lógica da circularidade expressa no aforismo de Maturana e Varela (1990, p.116): “Conhecer é viver. Viver é conhecer."

Em Humano, Demasiadamente Humano, Nietzsche coloca o devir ao mesmo tempo em que ataca a substância objetiva numa postura complexa:

Nós próprios nada somos senão aquilo que sentimos dessa correnteza a cada instante. Até mesmo aqui, se quisermos entrar no rio de nosso ser aparentemente mais próprio e mais pessoal, vale a proposição de Heráclito - não se entra duas vezes no mesmo rio. (NIETZSCHE, 1983, p.138-139)

Essas atitudes descritas implicam numa genealogia em oposição a origens fixadas no tempo. Em Nietzsche (1983) podemos identificar pressupostos complexos tais como a lógica circular expressa na idéia do Eterno Retorno e os rudimentos do princípio de auto-organização fundamental para o novo paradigma. Há na obra desse filósofo a afirmação da imanência e um rompimento com a coisa em si. No sentido da auto-organização 
podemos afirmar que Nietzsche (1983) derruba a possibilidade de representação como sugere claramente um princípio autopoiético através de um mundo visto a partir de dentro. Não é exatamente essa idéia que defendem Maturana e Varela $(1990,1995)$ ao tratar da invenção de cognição e de realidade? Foi por essa razão que eles cunharam o termo Autopoiesis.

Nesse caminho de busca da gênese da complexidade chegamos em Henri Bérgson, no começo do século $X X$, que elabora sua teoria com base na idéia de uma Evolução Criadora através de mecanismos vitais criativos. Ele criou o conceito de élan vital para mostrar o papel criador dos seres na evolução oferecendo uma idéia de uma cognição inventiva inseparável do movimento de devir evolutivo. Nesse sentido, Bergson (1979) destaca o papel da intuição na construção do ser e do conhecimento. Ilya Prigogine $(1979,1994)$ com suas teorias em termodinâmica vai resgatar muitas das idéias bergsonianas tornando-se um dos principais pilares do Movimento de Auto-organização.

\section{Tramando os Fios Teóricos do Complexus}

"Complexus é o que se tece junto." Edgar Morin

Para Morin (1991), o pensador da complexidade, as conseqüências da fragmentação da realidade praticada pela ciência moderna foi altamente deletéria. O paradigma da complexidade que emerge no século $X X$ começa a romper com as dicotomias e propõe uma abordagem holística da realidade (RORTY, 1979). Trata-se de um holismo epistemológico cuja presença pode ser identificado em diferentes teorias do Movimento de Auto-Organização.

A grande virada paradigmática, como já referido, se deu nos meados do século $X X$, entre os anos de 40 e 50, quando um grupo de cientistas originários de variados campos do conhecimento se reuniram durante 10 anos para fundar uma ciência da mente. Esses encontros ficaram conhecidos como as Macy`s Conferecences $^{1}$ e aconteceram, na sua maior

1 O nome oficial desses encontros era Circular Causal and Feedback Mechanisms in Biological and Social Systems parte, em Nova York. Dessa colaboração emergiram trabalhos científicos seminais que marcaram as mudanças de rumos na ciência que acabam por configurar um novo paradigma. O grupo chega à fundação de uma ciência, a primeira efetivamente complexa, porque uma composição de variadas ciências tais como a Matemática, a Epistemologia, a Psicologia, a Lingüística, a Antropologia, Neurologia e outras. Por sugestão de um dos membros mais atuantes do grupo, Norbert Wiener (1961), essa ciência passou a chamar-se de Cibernética. Esse movimento desdobrou-se numa segunda fase, a II Cibernética, configurada basicamente pelas idéias do austríaco Heinz Von Foerster (2003), chegado da Europa pela altura da quarta conferência.

A entrada de Von Foerster (op.cit) no grupo cibernético foi revolucionária porque não somente introduziu princípios e conceitos realmente perturbadores, como forçou o movimento na direção de uma complexidade radical ao conceber o princípio da ordem pelo ruído como também incluir o observador na realidade observada. Von Foerster (op.cit) defendeu com muita insistência a idéia de que os sistemas aprendem como o seu próprio operar. Esse fato fez com que o grupo ligado a Von Foerster se afastasse bastante do grupo inicial da cibernética que continuou perseguindo a questão da analogia do cérebro com o computador, o processamento de informações e o projeto de Inteligência Artificial. É importante lembrar aqui que a I Cibernética contribuiu de forma muito significativa para o novo paradigma através dos conceitos de causalidade circular e feedback bem como com a noção de conhecimento como complexo de operações opondo-se à idéia tradicional de que seria uma propriedade.

Von Foerster fundou a seguir o Biological Computer Laboratory (BCL) para pesquisar as idéias que vinha elaborando. Ele estava decidido a criar uma ciência dos sistemas observantes em contraposição à dos sistemas observados. Com isso, ele abre caminho para a constituição de uma epistemologia cibernética (DUPUY, 1996). Para trabalhar nesse centro de pesquisa ele convidou Maturana para quem essa experiência foi fundamental nas descobertas que fez após deixar o BCL.

As concepções de Von Foerster abriram caminho para as teorias complexas da biologia tais como a Teoria da Complexidade Pelo Ruído 
de Henri Atlan e a Biologia do Conhecer de Humberto Maturana e Francisco Varela².

Henri Atlan, um médico francês, que já vinha há algum tempo se aproximando do grupo cibernético estava muito preocupado em saber como os processos biológicos se autoorganizam. Partindo das idéias forsterianas de ruído como fonte de movimentos autoorganizativos a partir do aleatório, como também usando o formalismo da teoria da Informação, ele chegou à formulação de sua teoria da Complexificação Pelo Ruído e, na sequência, utilizou esses pressupostos para pensar numa aprendizagem que emerge com o trabalho sobre o ruído. O que Atlan (1979) realmente pretendia era entender a lógica da organização natural e que papel o ruído jogava nesse processo organizativo. Clara Oliveira capta muito bem o sentido do ruído e da complexificação em Atlan:

O ruído surge como um factor, um pretexto para o ser vivo crescer qualitativamente, complexificar-se face ao nível anterior em que ele se encontrava antes de ter sido perturbado o que se torna importante perceber é que esta transformação do ruído em significação não é feita em função de um programa pré-estabelecido que o ser vivo possuiria, mas trata-se antes de uma criação, de uma produção que se vai fazendo de modo completamente aleatório, apenas em função do estado em que o ser vivo se encontra naquele preciso momento, e com o material (componentes) e os processos já existentes (anteriormente criados) que efectuam a interação, e produção desses mesmos componentes. (OLIVEIRA, 1999, p. 362)

Mas, espinosiano como era, ele queria ir além - queria entender a organização em todos os níveis da realidade. À maneira de Espinosa ele considera que a natureza em sua totalidade e os modos que a compõem é tudo o que existe. Os modos são as partes singularizadas dessa substância única. Os modos podem ser um ser humano, um animal, uma árvore ou uma pedra. O que interessa é ver no interior desses modos o poder da natureza atuando. É aqui que nos interessa de modo especial para responder à questão formulada na medida em que queremos pensar a organização dos humanos e das coisas em geral para entendermos o papel da tecnologia.

Nesse processo de entender a cognição como uma questão complexa que articula

2 A primeira dessas teorias a ser publicada foi a de Henri Atlan no livro de 1971 - Organisation biologique et théorie de I'information. O livro com a publicação da teoria de Maturana e Varela é de 1972 e chamou-se De Máquinas e Seres Vivos. profundamente conhecer com viver a teoria de Maturana e Varela, a Biologia do Conhecer, foi um dos fatos paradigmáticos da maior significação na ciência contemporânea. Esse dois biólogos vão se afastar ainda mais do modelo cibernético inicial porque não concebem o sistema nervoso com entradas e saídas que capta informações. No entanto, continua sendo uma teoria cibernética devidos aos pressupostos envolvidos tais como a lógica circular, a recursividade, os mecanismos de feedback e auto-organização. Concebem, isso sim, o sistema nervoso como fechado e se auto-organizando a partir de perturbações do meio que, tal como já explicado, nunca são instrutivas ou determinantes. Sobre o papel dessa teoria no novo paradigma cito novamente Clara Oliveira:

O que realmente de significativo a teoria da autopoiesis trouxe para o movimento de auto-organização foi, como efeito, esta concepção do fecho dos sistemas vivos, e também a concepção maquínica deste tipo de sistemas. Assim, a explicação dos seres vivos não deve ser feita a partir de seus componentes, mas sim em função da lógica de manutenção de seus equilíbrios homeostáticos, que nos leva a produzir os processos que dão origem à constituição dos componentes necessários para o organismo a cada instante; esses componentes, por seu lado, reforçam a produção de novos processos, ou a continuação dos mesmos, conforme o que for mais significativo para a sobrevivência do organismo em cada instante de sua existência. (OLIVEIRA, 1999, p. 141-142)

Com essas palavras, a autora não somente mostra o papel dessa teoria no novo paradigma como também de forma muito didática define a teoria e o seu potencial cognitivo-ontológico. Esses pressupostos também nos dão subsídios para responder nosso problema em termos do funcionamento dos processos cognitivos em relação ao espaço digital.

\section{O Complexus, Seres Vivos, Máquinas e Natureza}

“O que importa aqui não é unicamente o confronto com uma nova matéria de expressão, é a constituição de complexos de subjetivação: indivíduo-grupo-máquinatrocas múltiplas, que oferecem à pessoa possibilidades diversificadas de recompor uma corporeidade existencial, de sair de seus impasses repetitivos, e, de alguma forma de se re-singularizar." Félix Guattari

A noção de máquina com a cibernética se transformou radicalmente. Não se trata mais de idéias dicotômicas da modernidade que opunha máquina a sistemas organizados 
que só podiam ser os sistemas vivos. As máquinas que se opunham aos seres vivos eram do tipo: relógio, pêndulo e mais tarde, a máquina a vapor e tudo o que seguiu-se à II revolução industrial. Surgiram as máquinas cibernéticas que se auto-organizavam através de mecanismos de controle, retroalimentação e servos-mecanismos. Esse acontecimento tem implicações profundas para a vida da humanidade.

Essa nova noção de máquinas organizadas e de máquinas naturais vai aparecer na obra dos biólogos que seguem a tradição da II cibernética como Atlan, Maturana e Varela. Atlan (1992) vai utilizar essas noções em sua teoria salientando que precisamos nos conscientizar das conseqüências filosóficas dessa nova postura em relação às máquinas. Maturana e Varela (1995) já na primeira versão da publicação de sua teoria vão intitular a obra de divulgação "De Máquinas e Seres Vivos".

Com a cibernética, portanto, um mesmo dispositivo lógico, pode ser usado para abordar a natureza, as coisas e os seres vivos. Esse é o caráter complexo, por excelência, dessa ciência. E aqui podemos então, fazer a ponte com Espinosa. Atlan dá importantes contribuições para esse debate ancorandose no seu conhecimento de Espinosa. Atlan coloca novas questões a partir dessa mudança de vértices sobre as máquinas que ele formula da seguinte maneira:

[ . . . ] o que diferencia uma "máquina natural", isto é um sistema vivo, de uma máquina artificial, entendendo-se que ambas são sistemas organizados e que, graças às novas máquinas artificiais, começamos a ter algumas idéias sobre o que é organização? [ . . . ] Essas questões sobre a lógica da organização buscam respostas simultaneamente válidas para os sistemas físicoquímicos não-vivos e para os sistemas vivos. (ATLAN, 1979, p. 24)

É a partir, portanto, dessa nova noção de máquina que não se separa dos seres que a produzem e que com ela se relacionam que abordarei a seguir as questões das relações epistêmicas e subjetivas dos sujeitos humanos e os computadores.

\section{Processos Cognitivo- Ontológicos e as Novas Tecnologias: a dança complexa dos diferentes modos de existir}

“Toda a cosmogênese pode ser imaginada como o ato de um só ser, indissoluvelmente material e espiritual (isto é, sensível), que se torna complexo. Imaginemos uma única substância (para empregar a palavra de Espinosa) girando em torno de si, dobrando-se, organizando-se de maneira cada vez mais complicada, chegando a produzir qualidades sensíveis cada vez mais vivas, depois de formas de consciências e consciências de formas cada vez mais vastas e sutis, para finalmente tomar consciência de si no humano que se concentra, no mais alto grau, o poder criativo e a capacidade de consciência dessa substância única."

Pierre Lévy

"Se ao longo de nossa existência soubemos compor essas partes de maneira a aumentar a nossa potência de agir, experimentamos então por isso mesmo muitas afecções que dependiam unicamente de nós mesmos, isto é, da parte intensa de nós mesmos." Gilles Deleuze

A idéia de Substância Única em Espinosa permeia todas as coisas. Os modos (singulares?) seriam apenas expressões de produção de diferença da própria substância. Trata-se de um mundo vivo que aprende e cresce pelas afecções a cada momento. Para Lévy, isso é possível porque nesse mundo existe uma "[ . .. ] relação de amor, com quem ele dança a cada segundo [ . . . ]" (LÉVY, 2001, p. 137). Essa substância é carregada de virtualidades no sentido que vai se potencializando com as afecções e as ações. Para Deleuze pensando espinosianamente:

[ . . . ] a posse formal dessa potência de agir e igualmente de conhecer emerge como o summum bonum; é nesse sentido que a Razão, em vez de flutuar ao acaso dos encontros, procura unir-nos às coisas e aos seres cuja relação se compõe diretamente com a nossa. (DELEUZE, 2002, p.61)

Mas que encontros são esses se meu foco é o ambiente digital? Em primeiro lugar, o ciberespaço é, por excelência, o lugar da inteligência coletiva (LÉVY, 1996). Por isso, esse é um espaço que propicia as afecções. É ai também que, ao navegar, percorremos caminhos topológicos em atividades que envolvem lógicas não-lineares. São caminhos que não estavam traçados previamente, que vamos criando ao caminhar respondendo às perturbações constante do meio. Ao responder a todo o momento a essas perturbações os 
sujeitos vão constituindo, autopoieticamente, a suas ontogenias. Pensando agora, então, nos dados de minhas experiências empíricas com os sujeitos referidos inicialmente ${ }^{3}$, poderia dizer que eles se envolvem em duas atividades básicas que são altamente potencializadoras de ser e de conhecer: auto-narrativas postadas nos blogs e caminhos hipertextuais a partir dos interesses despertados nos blogs. Nas primeiras, eles se constituem pela narratividade se conectando com o mundo virtual e com eles mesmos. A escrita de si é sempre um exercício de devir, de autoria e de complexificação pois vai produzindo diferença e, pela auto-consciência implicada através da qual vamos atingindo níveis cada vez mais elevados de percepção. Em segundo lugar, os caminhos pela rede vão desafiando os sujeitos a processos auto-organizativos que implicam em dimensões cognitivas e dimensões subjetivas. O que temos visto ao longo dessas pesquisas-intervenção é a transformação dos sujeitos em termos de aumento de autoestima, expressão de autoria, desenvolvimento de relações lógicas resultando num processo de transformação geral dos sujeitos que surpreendem os professores das escolas que freqüentam. Alunos antes considerados indisciplinados, desinteressados e com muita dificuldade de aprendizagem transformam-se mostrando-se após a experiência do projeto em sujeitos solidários e criativos (PELLANDA; GUSTSACK, 2005).

Esses fatos empíricos tem nos levado a refletir sistematicamente no nosso grupo de pesquisa ${ }^{4}$ no qual levantamos novas questões: como ocorre essas transformações? Que processo cognitivo está envolvido aí? Temos tentado responder a essas questões à luz do conceito de Autopoiesis e do pressuposto da complexificação pelo ruído. Mais recentemente, tenho me debruçado sobre as possibilidades de alargar esse entendimento com as idéias de Espinosa. Mas, de qualquer forma, não se trata mais, como argumenta Maturana (2004), de perguntar sobre o que conheço mas colocar a pergunta em termos de: como faço para

3 Os nomes das cidades e dos grupos de pesquisa envolvidos serão completados aqui apos a aceitação do artigo para evitar elementos que possam identificar o autor desse artigo

4 Grupo de Ações e Intervenções Autopoiéticas (GAIA) - coordenado pela autora, cadastrado pelo CNPq e em desenvolvimento na UNISC. O Sub-projeto em questão é o de Inclusão Digital. conhecer? Sherry Turkle, uma pesquisadora dessa temática no Massachussets Institute of Technology (MIT) coloca as mesmas preocupações com uma outra formulação: "Que tipo de pessoas estamos nos tornando?" (TURKLE, 1984, p. 13). O que esta pesquisadora está pensando está muito próximo dos pressupostos com os quais trabalhamos aqui: autopoiesis, relação constituinte sujeito/ máquina, constituição de si, perturbação e auto-organização porque ela pensa a relação com o computador de forma complexa: A maior parte das considerações sobre o computador
descreve-o como racional, uniforme delimitado por uma
lógica. Eu vejo o computador através uma luz diferente,
não em termos de sua natureza como um 'engenho
analítico', mas em termos de uma 'segunda natureza',
como um objeto evocativo, um objeto que fascina,
perturba a uniformidade e precipita o pensamento.
(TURKLE, 1984,P.13)

Com essas reflexões de Turkle tento resumir o que foi dito sobre as implicações cognitivas e subjetivas da relação com a máquina numa perspectiva complexa que não separa nada no universo: seres humanos, máquinas, coisas e natureza fazem parte de uma mesma realidade. Em outras palavras, tratam-se de processos transversais que configiuram uma realidade complexa sempre em devir.

\section{Bifurcações e Atratores Estranhos: para onde estamos indo?}

\footnotetext{
“A tecnologia tem um papel que é biológico no strictu sensu da palavra: tem o direito de ser incluída no esquema da natureza. Deste ponto de vista com está em concordância com Bergson, não existe mais qualquer distinção entre o artificial e o natural, entre a tecnologia e a vida, desde que todos os organismos são resultados de invenção; se existe alguma diferença, a vantagem está no lado do artificial."
}

Pierre Teilhard de Chardin

Procurei nesse artigo, em consonância com os pressupostos da complexidade, tratar de forma inseparável as questões do viver e do conhecer e, com isso, colocar a técnica como uma ampliação das nossas capacidades cognitivas e ontogênicas. Na perspectiva da Substância Única, portanto, a técnica viria reforçar o conatus entendido por Espinosa como o esforço para ser, ou nos termos complexos da atualidade, seria o processo de 
singularização e auto-constituição de cada um de nós. Nesse sentido, as tecnologias não ampliaram somente a nossa capacidade de conhecer, mas, também modificariam a nossa ontogenia pois estamos nos transformando em todas as nossas dimensões ao nos acoplarmos com a técnica. As tecnologias de si para usar as palavras de Foucault (1995), teriam a mesma função e, nestes termos, nós destacamos as auto-narrativas dos adolescentes da pesquisa referida como exemplo vivo dessas tecnologias.

Para usar uma linguagem termodinâmica concluo essas reflexões usando os conceitos de bifurcações e atratores estranhos. Foi a releitura da II Lei da Termodinâmica feita por Ilya Prigogine um dos acontecimentos mais importantes do paradigma da complexidade e deu a ele o Prêmio Nobel em 1977. Com seus estudos de reversão da entropia graças ao princípio da auto-organização ultrapassando as fronteiras do mundo físico-químico, Prigogine é considerado por Dupuy (1996) um integrante do Movimento de Auto-organização. Os estudos de Prigogine nos permitem ver a natureza se organizando em todos os níveis.

Prigogine vai buscar em Bergson e Teilhard de Chardin as idéias fundadoras de sua filosofia científica. Em Bergson, a noção de evolução criadora na natureza com a emergência de bifurcações a partir da qual são escolhidos caminhos que não estavam traçados à priori. Em Teilhard, a idéia da convergência em direção a uma nova humanidade, a um ultra-humano (PRIGOGINE, 2003). Entender a cultura atual a partir do ciberespaço nesses termos termodinâmicos nos ajuda a compreender nossas possibilidades humanas de autotransformação a partir de atividades de autoconstituição e de vontade ao atualizarmos as virtualidades do viver. Para Espinosa (1983), a inteligência e a vontade são uma coisa só. Nesse sentido, ele usa o conceito de conatus para se referir ao processo de potencialização dos seres, ou seja, por em movimento aquilo que existe em potencial na natureza a partir do qual os modos se singularizam sem se separar da Substância Única.

Podemos hoje identificar uma tendência auto-organizativa nesse espaço virtual aonde vai se configurando uma nova humanidade. Ainda que, aparentemente, convivamos na atualidade com muita violência, fundamentalismos de todas a ordem e intolerâncias, parece estar havendo uma complexificação que aponta para convergências onde, como atratores estranhos, em direção aos quais as coisas convergem, vão se formando alguns padrões novos que, na linguagem dos próprios atratores, apresenta uma bonita geometria. Essas metáfora poderia ser interpretada com os padrões de solidariedade e as idéias de uma realidade única cada vez mais presente na rede mundial de computadores. A emergência da preocupação com a constituição de si de forma inseparável com a preocupação com os outros, a consideração do outro como legítimo outro, como costuma dizer Maturana (1999b) e uma inteligência coletiva onde os conhecimentos que circulam na rede vão se potencializando pelas afecções, tudo isso vai convergindo para uma nova cultura.

Aqui podemos fazer uma ponte entre a humanidade e a vida de cada um de nós apelando para as idéias de Prigogine:

O possível é mais rico que o real. A natureza apresentanos, de fato, a imagem da criação, da imprevisível novidade. Nosso universo seguiu um caminho de bifurcações sucessivas: poderia ter seguido outros.

Talvez possamos dizer o mesmo sobre a vida de cada um de nós. (PRIGOGINE, 1996, p. 74)

É nessa perspectiva que tenho pensado as atividades dos adolescentes na Internet, escrevendo sobre si para os outros, buscando caminhos, respondendo às auto-perturbações na rede, se transformando a cada dia, aprendendo a lidar com seu cotidiano penoso, encontrando prazer nas atividades de estudo, melhorando suas relações com os outros, produzindo sentido enfim naquilo que antes não viam nenhum. O espaço virtual, como em tudo na vida, se bem aproveitado pode nos potencializar.

\section{Referências}

ATLAN, H. L'organisation biologique et la theorie de l'information. Paris: Hermann, 1972.

ATLAN, H. Entre o Cristal e a Fumaça. Rio de Janeiro: Zahar, 1992. 
BATESON, G. Spiritu y naturaleza. Buenos Aires: Amorrotu, 1991.

BATESON, G. Metadiálogos. 3. ed. Lisboa: Gradiva, 1996.

BATESON, G.; BATESON, M.C. El temor de los Angeles. Barcelona: Gedisa, 2000.

BERGSON, H. A Evolução Criadora. Rio de Janeiro: Zahar, 1979.

DELEUZE, G. Espinosa: filosofia prática. São Paulo: Escuta, 2002.

DUPUY, J.-P. Nas Origens das Ciências Cognitivas. São Paulo: UNESP, 1996.

ESPINOSA, B. Ética. São Paulo: Abril, 1983.

FOUCAULT, M. Tecnologias del yo y otros textos afines. 2. ed. Barcelona: Paidós, 1995.

GUATTARI, F. Caosmose: um novo paradigma estético. São Paulo: Ed. 34, 1992.

LÉVY, P. As Tecnologias da Inteligência. São Paulo: Ed. 34, 1994.

LÉVY, P. O que é o Virtual. São Paulo: Ed. 34, 1996.

LÉVY, P. A Inteligência Coletiva. São Paulo, Loyola, 1996.

LÉVY, P. Cibercultura. São Paulo: Ed. 34, 1999.

LÉVY, P. A Conexão Planetária. São Paulo: Ed. 34, 2001.

MATURANA, H. Emociones y lenguaje en educacion y poltica. Santiago: Hachette, 1991.

MATURANA, H. El sentido de lo humano. Santiago: Dolmen, 1994.

MATURANA, H. Entrevista a Manuel Guzmán. Revista de Educación, Santiago, n. 223, p. 16-19, sept. 1995.

MATURANA, H. Biologia da Autoconsciência. In: PELLANDA, N.M.C.; PELLANDA, L.E.C. (Org.) Psicanálise Hoje: uma revolução do olhar. Petrópolis: Vozes, 1996.

MATURANA, H. La realidad: objectiva o construida? Santiago: Anthropos, 1997. V. 1-2.

MATURANA, H. Da Biologia à Psicologia. Porto Alegre: Artes Médicas, 1998.

MATURANA, H. A Ontologia da Realidade. Belo Horizonte: UFMG, 1999a.

MATURANA, H. Transformaciones en la convivencia. Caracas: Dolmen, 1999b.

MATURANA, H. Cognição, Ciência e Vida Cotidiana. Belo Horizonte: UFMG, 2001.

MATURANA, H.; PORKSEN, B. Del ser al hacer. Santiago: J.C. Saez, 2004.

MATURANA, H.; VARELA, F. Autopoiesis and cognition: The realization of the living. London: D. Reidel, 1980.

MATURANA, H.; VARELA, F. El arbol del conocimiento. Santiago: Universitaria, 1990.

MATURANA, H.; VARELA, F. De maquinas y seres vivos. Santiago: Universitária, 1995.

MORIN, E. Introdução ao Pensamento Complexo. Lisboa: Instituto Piaget, 1991. 
NIETZSCHE, F. Obras Incompletas. 3. ed. São Paulo: Abril Cultural, 1983. (Os Pensadores)

OLIVEIRA, C. da C. A Educação Como Processo Auto-organizativo. Lisboa: Instituto Piaget, 1999.

OLIVEIRA, C.C. Auto-organização, Educação e Saúde. Coimbra: Ariadne, 2004.

OLIVEIRA, C.C. (Uma) Biologia dos Afectos. In: FERREIRA, M.L. et al. Crescer nos Afectos. Coimbra: Ariadne, 2005.

PELLANDA, N.M.C; GUSTSACK, F. Autopoiesis e Mundo Digital: linguagens do afeto e da cognição em rede. [S.I.: s.n.], 2005. Trabalho apresentado no IADIS, Lisboa, 2005.

PELLANDA, N.M.C.; PELLANDA, L.E.C. (Org.). Psicanálise Hoje: uma revolução do olhar. Petrópolis: Vozes, 1996

PRIGOGINE, I. O Fim das Certezas. São Paulo: UNESP, 1996.

PRIGOGINE, I. Is future given? New, Jersey: World Scientific, 2003.

RORTY, R. Philosophy and the Mirror of Nature. Princeton: University of Princeton Press, 1979.

SAFRANSKI, R. Nietzsche: biografia de uma tragédia. São Paulo: Geração Ed., 2001.

SHULLER, D. Heráclito e seu (dis) curso. Porto Alegre, LP\&M, 2000.

TEILHARD DE CHARDIN, P. L'avenir de I'homme. Paris: Seul, 1959.

TEILHARD DE CHARDIN, P. El fenomeno humano. Barcelona: Taurus, 1974.

TURKLE, S. The second self. New York: Simon and Shuster, 1984.

VARELA, F. Conhecer. Lisboa: Instituto Jean Piaget, 1990.

VARELA, F. Ética y acción. Santiago: Dolmen, 1996.

VARELA, F. El Fenómeno de la Vida. Santiago: Dolmen, 2000.

VARELA, F. et al. The Embodied Mind. Cambridge, MA: The MIT Press, 1991.

VON FOERSTER, H. Principles of Self-Organization. New York: Pergamon Press, 1962.

VON FOERSTER, H. Ethics and Second Order-Cybernetics in Constructions of the Mind: Artificial Intellegence and the humanities. Stanford Humanities Review, Stabford, v. 4, n. 2, p. 308-319, 1995.

VON FOERSTER, H. Las semillas de la cibernetica. Barcelona: Gedisa, 1996.

Von FOERSTER, H. Understanding Understanding. New York: Spring-verlag, 2003.

WIENER, N. Cybernetics. Boston: MIT Press, 1961

Recebido em agosto de 2009

Aprovado para publicação em setembro de 2009 